\title{
Influence of medium range transport of particles from nucleation burst on particle number concentration within the urban airshed
}

\author{
H. C. Cheung ${ }^{1,}$, L. Morawska ${ }^{1}$, Z. D. Ristovski ${ }^{1}$, and D. Wainwright ${ }^{2}$ \\ ${ }^{1}$ International Laboratory for Air Quality and Health, Queensland University of Technology, Brisbane, QLD 4001, Australia \\ ${ }^{2}$ Queensland Department of Environmental Resource and Management, Australia \\ * now at: Research Center for Environmental Changes, Academia Sinica, Taipei 115, Taiwan
}

Correspondence to: L. Morawska (1.morawska@qut.edu.au)

Received: 19 September 2011 - Published in Atmos. Chem. Phys. Discuss.: 14 December 2011

Revised: 11 April 2012 - Accepted: 21 May 2012 - Published: 7 June 2012

\begin{abstract}
An elevated particle number concentration (PNC) observed during nucleation events could play a significant contribution to the total particle load and therefore to the air pollution in the urban environments. Therefore, a field measurement study of PNC was commenced to investigate the temporal and spatial variations of PNC within the urban airshed of Brisbane, Australia. PNC was monitored at urban (QUT), roadside (WOO) and semi-urban (ROC) areas around the Brisbane region during 2009. During the morning traffic peak period, the highest relative fraction of PNC reached about $5 \%$ at QUT and WOO on weekdays. PNC peaks were observed around noon, which correlated with the highest solar radiation levels at all three stations, thus suggesting that high PNC levels were likely to be associated with new particle formation caused by photochemical reactions. Wind rose plots showed relatively higher PNC for the NE direction, which was associated with industrial pollution, accounting for $12 \%, 9 \%$ and $14 \%$ of overall PNC at QUT, WOO and ROC, respectively. Although there was no significant correlation between PNC at each station, the variation of PNC was well correlated among three stations during regional nucleation events. In addition, PNC at ROC was significantly influenced by upwind urban pollution during the nucleation burst events, with the average enrichment factor of 15.4. This study provides an insight into the influence of regional nucleation events on PNC in the Brisbane region and it the first study to quantify the effect of urban pollution on semi-urban PNC through the nucleation events.
\end{abstract}

\section{Introduction}

Atmospheric aerosols have been reported to be significantly associated with the alteration of climate forcing and the degradation of visibility, as well as the deterioration of human respiratory and cardiovascular systems (Charlson et al., 1992; Donaldson et al., 1998; Watson 2002). Due to their small size $(<0.1 \mu \mathrm{m})$, ultrafine particles (UFPs) only contribute a very small amount to the total mass of atmospheric particles, however they are most abundant by number $(\sim 70$ $90 \%$ ) and potentially have a greater impact on human health than the larger particles $(<2.5 \mu \mathrm{m})$ (Morawska et al., 2008).

In urban environments, vehicle exhaust emissions are the most significant source of UFP and variations in particle number concentration (PNC) are strongly associated with local urban traffic activity (Morawska et al., 1998, 2008). Aircraft/ship emissions also contribute to elevated PNCs at a magnitude of $10^{5}-10^{6} \mathrm{~cm}^{-3}$ (Sinha et al., 2003; Mazaheri et al., 2009). In addition to direct emission from above sources, new particles formed by nucleation processes is another source of UFPs in the urban environment, with PNC reaching magnitudes as high as $10^{4}-10^{5} \mathrm{~cm}^{-3}$ during nucleation events (Qian et al., 2007; Pey et al., 2009; Cheung et al., 2011). In previous studies, particle mass concentration has been studied with regard to long range transport in an intercontinental scale (Jaffe et al., 2003), however the size distribution of and temporal-spatial variations in PNC have only been investigated on a local scale (Morawska et al., 1998; Hussein et al., 2004). For example, although regional nucleation has been observed in Helsinki, Finland (Hussein et al., 2008), Atlanta and Pittsburgh, United States of America

Published by Copernicus Publications on behalf of the European Geosciences Union. 
(Stolzenburg et al., 2005; Stanier et al., 2004), spatial variations in PNC have also been studied in urban areas in Australia (Mejía et al., 2008) and in the United States (Hudda et al., 2010). These studies have not examined the impact of regional pollution on PNCs or the influence upwind urban pollution has on PNC downwind during the nucleation events.

This study aimed to examine the effect of regional pollution on PNC in different environments in the Brisbane region. After characterising the spatial variation of PNC in three different urban locations, we went on to investigate the influence of regional nucleation on PNC in the same region. Furthermore, the impact of urban pollution on PNC downwind from a semi-urban area during a nucleation burst event was also quantified. The results of this study are valuable for assessing the impact of nucleation on PNC in an urban environment.

\section{Methods and techniques}

\subsection{Study design}

Field measurements of particles and gaseous pollutants were conducted at three locations in Brisbane in 2009 to represent the urban (1 January to 31 December 2009), roadside (21 May to 31 December 2009) and semi-urban environments (5 February to 31 December 2009).

\subsection{The topography and meteorology of the Brisbane region}

Brisbane is located at $27^{\prime} 30^{\circ} \mathrm{S}$ and $153^{\circ} \mathrm{E}$, at Queensland of Australia. Brisbane city is surrounded by mountains from south to north, and faces the Pacific Ocean to the East. Traffic exhaust emissions are the major pollution source affecting the central business district (CBD). In addition, the aircraft, ship and industrial emissions are occasionally transported from the lower reaches of the Brisbane River, approximately $15-18 \mathrm{~km}$ NE of the CBD, by inland sea breezes. General wind patterns in the Brisbane region are governed by land and sea breezes, which are described in more detail by Morawska et al. (1998).

\subsubsection{Brisbane CBD (urban general)}

The measurements were conducted at the International Laboratory of Air Quality and Health (ILAQH), Queensland University of Technology (QUT), which is within the Brisbane CBD (Fig. 1). The monitoring site is on the sixth floor of a QUT campus building, located SE of the city centre, with a major highway (the Pacific Motorway) situated along the SW side of the campus. Therefore, the pollution associated with $\mathrm{NE}$ winds could be attributed to industrial emissions (from the airport, oil refinery and Port of Brisbane), while the pol- lution associated with $\mathrm{S}$ to NW winds could be attributed to local traffic exhaust emissions.

\subsubsection{Woolloongabba (roadside)}

The Woolloongabba (WOO) monitoring station is located $3 \mathrm{~km}$ south to Brisbane CBD, and it is a part of the South-East Queensland air monitoring network of the Department of Environmental Resource and Management (DERM). The monitoring station is situated about $5 \mathrm{~m}$ from the kerb of Ipswich road, a road with a heavy traffic flow volume of over 40000 , connecting the Southern Brisbane suburbs to the CBD. A relatively higher PNC level was expected at this site due to the significant impact of vehicle emission on PNC. In addition, a mutli-storey car park located 10 meters to the West of the station, and large scale road works surrounding the station, could also influence particle pollution levels.

\subsubsection{Rocklea (semi-urban)}

The Rocklea (ROC) monitoring station is located around $10 \mathrm{~km}$ south of the Brisbane CBD and was also operated by the DERM. This station is surrounded by an open area, and the particle concentration was deemed to be free from the influence of local emissions. The major emission sources are from light industrial (Brisbane farmers markets) and residential (domestic cooking) sources in the Rocklea area.

\subsection{Measurement techniques}

UFP size distribution in the range 4-110 $\mathrm{nm}$ was measured at the QUT monitoring site using a Scanning Mobility Particle Sizer (SMPS), which consisted of two parts, an Electrostatic Classifier (EC) (TSI 3080) equipped with a nano-Differential Mobility Analyser (nano-DMA) and a Condensation Particle Counter (CPC) (TSI 3781). Ambient air was drawn through a $\sim 1 \mathrm{~m}$ long conductive tubing connected to the EC. The ratio of the aerosol/sheath air flow for the EC was kept at 1/10 (0.6 to $61 \mathrm{~min}^{-1}$ ), and the scan time was five minutes. The size distribution data is then used to calculate PNC for the QUT site. At the WOO and ROC stations, PNC is continuously measured by a water-based CPC (TSI 3781) with a size-cut inlet of $1 \mathrm{~nm}$, while particle mass concentrations of $\mathrm{PM}_{2.5}$ and $\mathrm{PM}_{10}$ are measured by a Tapered Element Oscillating Microbalance (TEOM) in 30-min intervals at each site.

Gaseous pollutants, such as carbon monoxide (CO) and nitrogen oxide $\left(\mathrm{NO}_{\mathrm{x}}\right)$, were measured at WOO; and ozone $\left(\mathrm{O}_{3}\right)$ and $\mathrm{CO}$ were measured at ROC using real-time gaseous analysers (Ecotech ML9830 for CO; Ecotech ML9841/ API 200A for $\mathrm{NO}_{\mathrm{x}}$; Ecotech ML9812 for $\mathrm{O}_{3}$ ). Meteorological parameters, including wind direction/speed, temperature, relative humidity and solar radiation, have also been measured. The data were collected and validated by the DERM. 


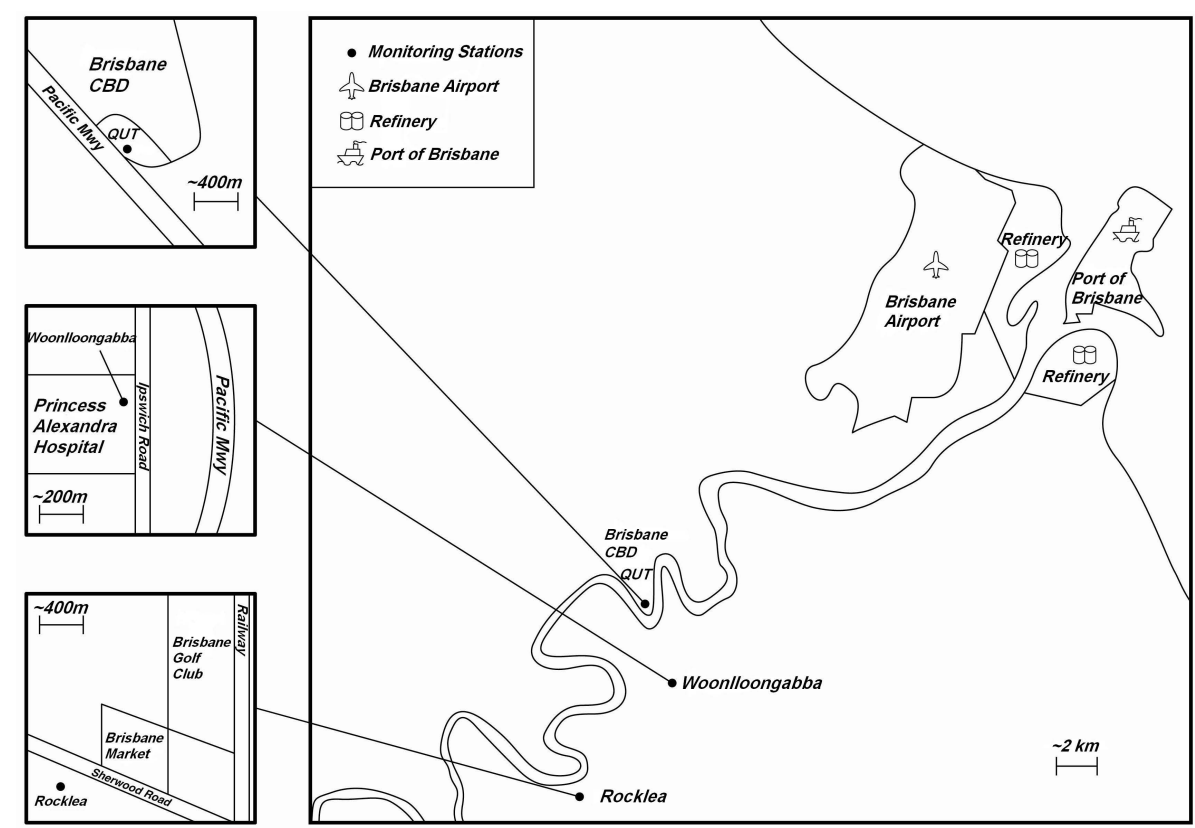

Fig. 1. Map of monitoring sites.

\subsection{Data processing and analysis}

The raw particle size distribution measurements were transformed into $10 \mathrm{~min}$ averaged data for figure plotting. The total PNC for QUT was calculated by adding all of the particle counts in each size bin, which had a lower and upper limit of $1 \mathrm{~cm}^{-3}$ and $5 \times 10^{5} \mathrm{~cm}^{-3}$, respectively (Mejía et al., 2007). Approximately $28 \%$ of the data removed from the database was based on the following criteria (the contribution of each quality control is shown in brackets): (i) if the particle concentration has a zero value $(\sim 2 \%)$; (ii) if the particle concentration is higher than $5 \times 10^{5} \mathrm{~cm}^{-3}(<1 \%)$; (iii) and if data has been collected during instrument malfunction $(\sim 26 \%)$. Since the time resolutions of the particle mass concentration, gaseous and meteorological data provided by the DERM were in 30 min intervals, all measurements were transformed into $30 \mathrm{~min}$ averaged data for the correlation analysis (Sect. 3.2). Since the PNCs measured at three sites were using SMPS and CPC, to remove the discrepancy of these measurement methods, a relative PN contribution to total PNC has been used in temporal and correlation analysis. Inter-comparison between the PNCs measured by SMPS and CPCs has been shown in Fig. S1; moderate correlations have been obtained $\left(r^{2}=0.47-0.81\right)$ with slopes of 0.55-0.65. This implies that the method of using PNCs measured by SMPS and CPCs for correlation analysis is justifiable and the ultrafine particles accounted for more than $50 \%$ of the PNC (by using CPC). Correlations between the parameters were tested using the Pearson correlation test, with a $95 \%$ confidence level $(p<0.05)$. The linearity of the tested parameters was indicated by the product of Pearson's coefficient, $r^{2}$, with a perfect linear correlation between two parameters indicated by an $r^{2}$ value close to 1 . It should be noted that the PNC data for WOO is missing for the months from January to April due to instrument malfunction.

The back-trajectory of various air masses was calculated by using the HYSPLIT model (Hybrid Single Particle Lagrangian Integrated Trajectory, Version 4.9), in order to trace their origin. The meteorological data used for back-trajectory calculations was $1^{\circ} \times 1^{\circ}$ in latitude and longitude. The calculated trajectory analysis provided an indication of which region the air mass came from. For the detail information about the principle and operation of HYSPLIT model was refereed to these articles (Draxler and Hess 1997, 1998; Draxler 1999).

\section{Results and discussion}

Firstly, the variation in PNC within each location was investigated by analysing the diurnal variation together with other measured parameters. Secondly, correlations between PNC for the different locations were examined, along with the influence of wind direction on PNC. Finally, two cases which represented typical regional nucleation events and the transport of urban pollution to the downwind semi-urban site were investigated.

\subsection{Diurnal variation}

Diurnal variations of PNC measured at the three locations, which have been classified into (a) weekdays and (b) weekends by all measured data, are illustrated in Fig. 2. It should 


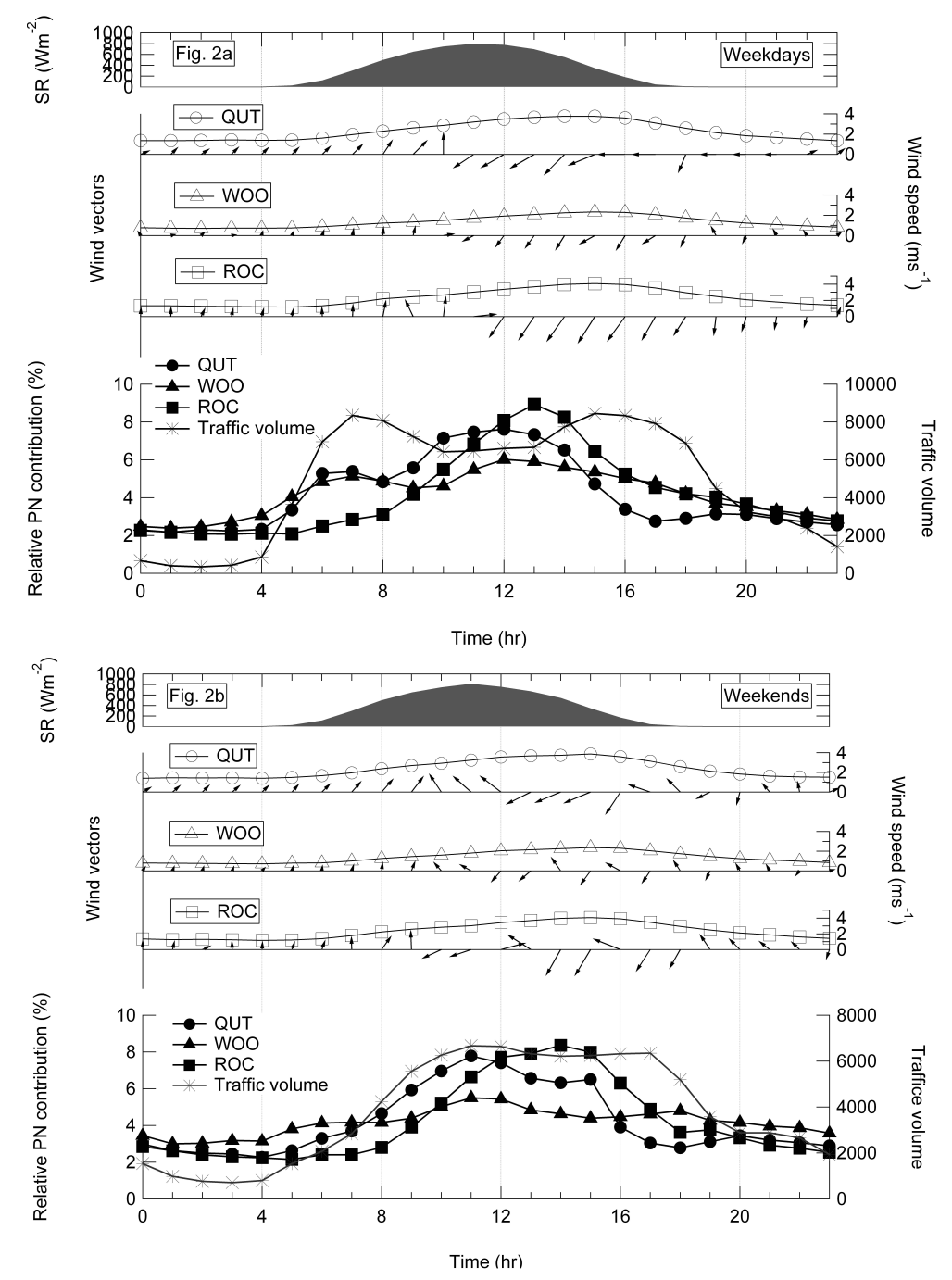

Fig. 2. Average diurnal variation of parameters measured for (a) weekdays and (b) weekends. From bottom to top: (i) relative PNC measured at three sites, together with traffic volumes recorded at QUT; (ii) wind vectors measured at the three sites; and (iii) solar radiation (SR) measured at ROC.

be noted that the measurement periods at each site did not overlap. The general meteorological conditions for weekdays and weekends were similar, with SE-winds observed in the morning and NE-winds observed around noon, while solar radiation reached a maximum at noon on all days. In contrast, traffic volumes differed during the weekdays and weekends, such that: (i) traffic volumes were higher during weekdays than weekends; (ii) the daily traffic volume pattern consisted of two peaks during weekdays, one in the morning ( 06:00-07:00 a.m.) and one in the afternoon (around 03:00-06:00 p.m.); and (iii) the daily pattern during weekends consisted of a wide broader peak.

In Fig. 2a, it can be seen that morning PNC peaks were observed both at QUT and WOO. During that period, the measured relative fraction of PNC was found to be nearly $5 \%$ for both sites, however they were not found at ROC. This result suggests that the observed peaks are related to morning traffic activity on nearby roads. Around noon, PNC peaks were observed at all three locations, as well as the maximum solar radiation. The highest relative fraction of total PNC at noon is $7.6 \%, 6.0 \%$ and $8.9 \%$ for QUT, WOO and ROC locations, respectively. These peaks are likely to be the result of new particle formation caused by photochemical reactions (Cheung et al., 2011). It should be noted that the relative fraction of the total PNC is affected by background PNC, traffic emissions and photochemical particle production during the morning and noon periods. The maximum PNC observed at QUT and WOO is at 12:00, and at 13:00 for ROC. The time lag at ROC could be the result of the time the pollution plume requires to be transported from the upwind area (CBD area), to the downwind area (ROC). This is discussed in more detail in Sect. 3.5. 


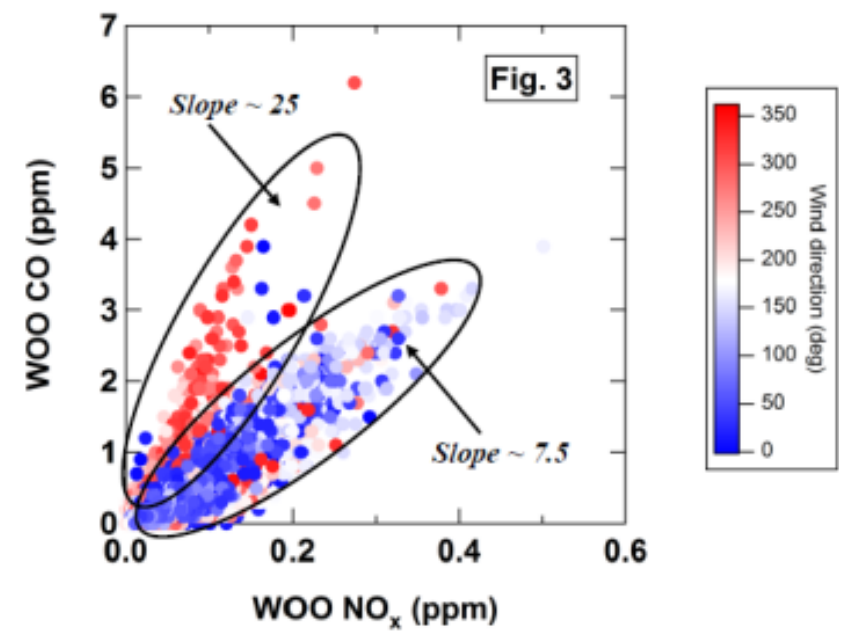

Fig. 3. Scatter plots of $\mathrm{CO}_{\mathrm{WOO}}$ versus $\mathrm{NO}_{\mathrm{x}}$, wOO

One interesting observation was that the influence of traffic activity was weak during the afternoon period $(\sim 15: 00$ 18:00) for both weekdays and weekends, with PNC found to decrease gradually between 14:00-15:00, even though traffic volume remained relatively unchanged. Similar observations were made in the urban area of Helsinki, Finland (Hussein et al., 2004).

\subsection{Correlation among measured parameters}

A summary of the correlation coefficients $\left(r^{2}\right)$ for the measured parameters from the entire period is provided in Table 1 . The low $r$ values, $0.05<r^{2}<0.19$, showed that the $\mathrm{PNC}$ at the three sites were not correlated, however $\mathrm{PM}_{2.5}$ and $\mathrm{PM}_{10}$ at WOO and ROC were well correlated $(0.60<$ $\left.r^{2}<0.88\right)$. These results implied that the PNC at each site were generally influenced by local sources, such as vehicle exhaust emissions (Morawska et al., 2008), while $\mathrm{PM}_{2.5}$ and $\mathrm{PM}_{10}$ were influenced by intra-city pollution.

Although there was no correlation between PNC at the three sites, it did appear to be influenced by regional pollution during the nucleation events (discussed in Sect. 3.4). PNC at QUT and ROC did not show a significant correlation with primary gaseous pollutants such as $\mathrm{CO}$ and $\mathrm{NO}_{\mathrm{x}}$, but PNC did show a moderate correlation with $\mathrm{CO}(r=0.35)$ and $\mathrm{NO}_{\mathrm{x}}(r=0.47)$ at WOO. The results observed for QUT are in contrast to those reported by Morawska et al. (1998), where PNC (5-1000 nm) at QUT was reasonably well correlated with $\mathrm{CO}(r=0.45)$ and $\mathrm{NO}_{\mathrm{x}}(r=0.40)$ and was also influenced by vehicle exhaust emission. This discrepancy may be due to the different measurement periods, as the measurements were only conducted during the morning and afternoon peak traffic hours in Morawska et al. (1998). However, a continuous measurement approach was used in the present study, which included a more complex mixture of emissions and a significant contribution to PNC by nu- cleation process, which may have masked the influence of vehicle exhaust emissions on PNC.

Furthermore, scatter plots (Fig. 3) for carbon monoxide and nitrogen oxide at WOO show the influence of two pollution plumes with different $\mathrm{CO} / \mathrm{NO}_{\mathrm{x}}$ ratios as a function of wind direction. The $\mathrm{CO} / \mathrm{NO}_{\mathrm{x}}$ ratios for these two groups were $\sim 25$ and 7.5 , respectively. The first group (ratio 25) was associated with winds from the SW to NW, while the second group (ratio 7.5) was mainly associated with NE winds. Given that the vehicle exhaust emission ratio in SE Queensland is about 10 (Cheung et al., 2011), it is likely that the second group was affected by vehicle exhaust emissions. Since low speed driving induces higher $\mathrm{CO} / \mathrm{NO}_{\mathrm{x}}$ ratios than faster driving modes (Holmén and Niemeier 1997), this could be a result of vehicle emissions from the hospital car park, located $10 \mathrm{~m} \mathrm{~W}$ of WOO. It should be noted that, in the absence of in-situ measurements, this explanation is only speculative.

\subsection{Dependence of the particle number concentration on wind direction}

The wind rose plots for PNC showed a similar pattern for the three sites (see Fig. 4a), with all three sites affected by both land and sea breezes, which blew from the SW and NE, respectively (see Fig. 4b). In general, relatively higher concentrations were observed in the NE quadrant, being $12 \%, 9 \%$ and $14 \%$ for QUT, WOO and ROC, respectively, compared to around 3-6\% for the other three quadrants. This result implies that, in addition to the local sources at each site, there was a significant source located in a NE direction of the sites. This is most likely the result of the numerous industrial activities (i.e. Port of Brisbane, Oil Refinery, and Domestic and International Airports) taking place NE of all three sites, as well as from traffic emissions from the CBD, which is also upwind from WOO and ROC.

\subsection{Influences of regional pollution on the particle number concentration}

During 2009, a total of 40 nucleation growth events were observed based on particle size distribution data for QUT in Brisbane (Cheung et al., 2011) and more detailed information regarding the classification of nucleation events can be found in this paper. In order to further investigate the influence of nucleation growth events on the PNC of Brisbane region, we chose two nucleation events as case studies, one which occurred on 17 July 2009 and the other on 9 September 2009. The first case was a region wide event, while the second case was a local event. A Pearson's correlation coefficient was calculated for each event, using data obtained between 08:00-16:00, since the majority of nucleation events were initiated during this period. From Table 2 it can be seen that PNCs at the three sites showed significant correlations during some nucleation events. For example, the $r^{2}$ values for QUT-ROC, QUT-WOO and WOO-ROC were 0.95, 0.71 and 


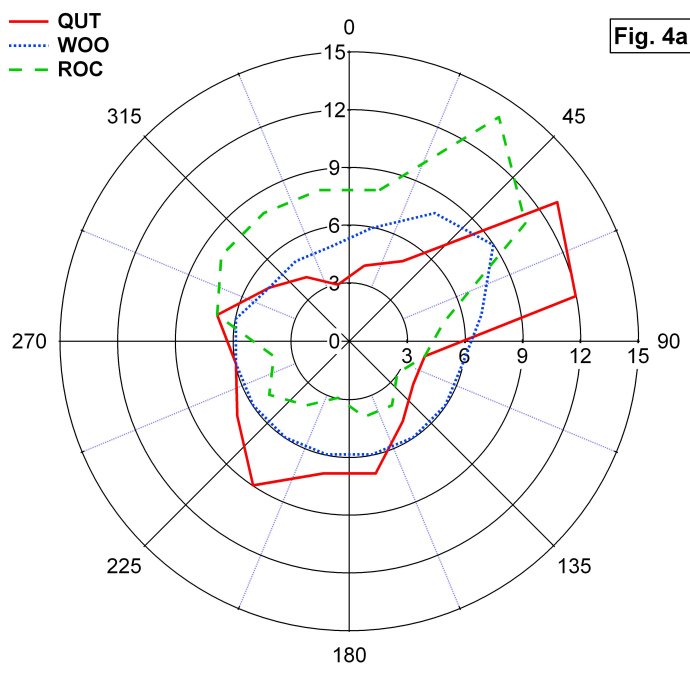

Wind rose plot of the relative contribution of PN (\%)

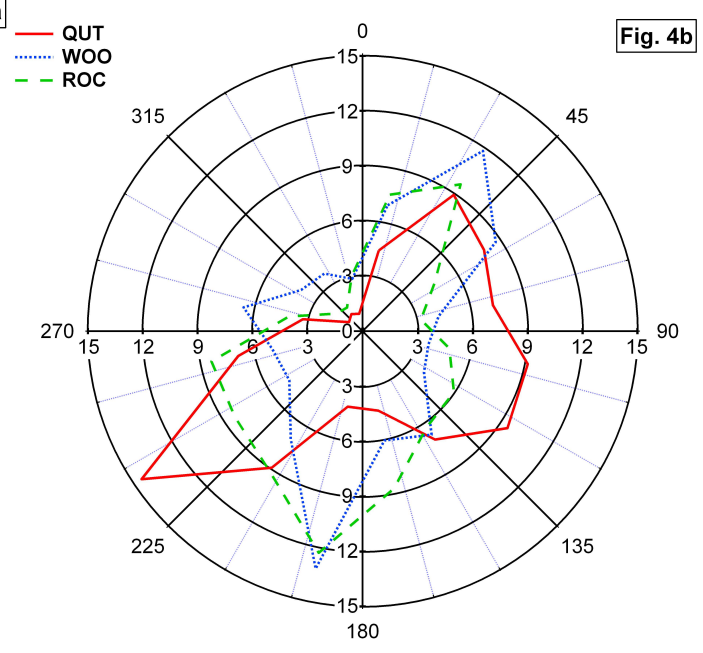

Wind rose plot of relative frequencies of wind direction (\%)

Fig. 4. Wind rose plots of (a) relative PNC contribution at QUT, WOO and ROC; (b) relative frequencies of wind direction.

Table 1. $r^{2}$ calculated between the parameters.

\begin{tabular}{|c|c|c|c|c|c|c|c|c|c|c|c|c|c|}
\hline & $\mathrm{N}_{\mathrm{QUT}}$ & $\mathrm{N}_{\text {WOO }}$ & $\mathrm{N}_{\mathrm{ROC}}$ & $\begin{array}{r}\mathrm{PM}_{10} \\
(\mathrm{QUT})\end{array}$ & $\begin{array}{r}\mathrm{NO}_{\mathrm{x}} \\
(\mathrm{WOO})\end{array}$ & $\begin{array}{r}\mathrm{CO} \\
(\mathrm{WOO})\end{array}$ & $\begin{array}{r}\mathrm{PM}_{2.5} \\
(\mathrm{WOO})\end{array}$ & $\begin{array}{r}\mathrm{PM}_{10} \\
(\mathrm{WOO})\end{array}$ & $\begin{array}{r}\mathrm{NO}_{\mathrm{x}} \\
(\mathrm{ROC})\end{array}$ & $\begin{array}{r}\mathrm{O}_{3} \\
(\mathrm{ROC})\end{array}$ & $\begin{array}{l}\mathrm{PM}_{2.5} \\
(\mathrm{ROC})\end{array}$ & $\begin{array}{l}\mathrm{PM}_{10} \\
(\mathrm{ROC})\end{array}$ & RAD \\
\hline $\mathrm{N}_{\mathrm{QUT}}$ & 1.00 & 0.05 & 0.19 & 0.00 & 0.02 & 0.00 & 0.00 & 0.00 & 0.00 & 0.02 & 0.00 & 0.00 & 0.08 \\
\hline $\mathrm{N}_{\text {WOO }}$ & & 1.00 & 0.12 & 0.00 & 0.22 & 0.12 & 0.01 & 0.00 & 0.03 & 0.01 & 0.00 & 0.00 & 0.07 \\
\hline $\mathrm{N}_{\mathrm{ROC}}$ & & & 1.00 & 0.00 & 0.04 & 0.03 & 0.00 & 0.00 & 0.01 & 0.08 & 0.00 & 0.00 & 0.12 \\
\hline $\mathrm{PM}_{10}(\mathrm{QUT})$ & & & & 1.00 & 0.00 & 0.00 & 0.12 & 0.17 & 0.00 & 0.01 & 0.13 & 0.14 & 0.00 \\
\hline $\mathrm{NO}_{\mathrm{x}}(\mathrm{WOO})$ & & & & & 1.00 & 0.65 & 0.05 & 0.00 & 0.31 & 0.02 & 0.01 & 0.00 & 0.00 \\
\hline $\mathrm{CO}$ (WOO) & & & & & & 1.00 & 0.02 & 0.00 & 0.20 & 0.01 & 0.00 & 0.00 & 0.01 \\
\hline $\mathrm{PM}_{2.5}(\mathrm{WOO})$ & & & & & & & 1.00 & 0.80 & 0.03 & 0.00 & 0.79 & 0.60 & 0.01 \\
\hline $\mathrm{PM}_{10}(\mathrm{WOO})$ & & & & & & & & 1.00 & 0.00 & 0.00 & 0.88 & 0.80 & 0.00 \\
\hline $\mathrm{NO}_{\mathrm{x}}(\mathrm{ROC})$ & & & & & & & & & 1.00 & 0.27 & 0.01 & 0.00 & 0.06 \\
\hline $\mathrm{O}_{3}(\mathrm{ROC})$ & & & & & & & & & & 1.00 & 0.01 & 0.00 & 0.38 \\
\hline $\mathrm{PM}_{2.5}(\mathrm{ROC})$ & & & & & & & & & & & 1.00 & 0.83 & 0.00 \\
\hline $\mathrm{PM}_{10}(\mathrm{ROC})$ & & & & & & & & & & & & 1.00 & 0.00 \\
\hline RAD & & & & & & & & & & & & & 1.00 \\
\hline
\end{tabular}

0.75 on 17 July 2009 respectively (with $p<0.05$ ). To better illustrate the correlation of PNCs from different locations (urban and downwind semi-urban areas) during nucleation and non-nucleation events, an example of the PNC scatterplot obtained during the event and non-event days at QUT and ROC is shown in Fig. S2.

As shown in Fig. 5a, similar temporal variations were observed on 17 July 2009, when a nucleation growth event was observed at 10:30. At this time the relative PNC at QUT, WOO and ROC increased from $1.5 \%$ to $8 \%, 2 \%$ to $5 \%$ and $1.5 \%$ to $10 \%$ at each station, respectively, before returning to around $1.5 \%$ for each site at approximately 16:00.

In contrast, there were some instances where the $r^{2}$ was larger than 0.5 for QUT-ROC $\left(r^{2}=0.79\right)$, but lower for QUT-WOO $\left(r^{2}<0.01\right)$ (e.g. 9 September 2009). In addition, the temporal variation for $\mathrm{PN}_{\mathrm{QUT}}$ and $\mathrm{PN}_{\mathrm{ROC}}$ were closely correlated during the period between 10:30-15:30

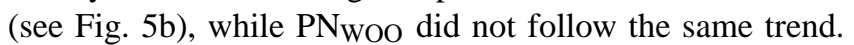
This indicates that there was a regional pollution plume that affected QUT and ROC, but not WOO, which was located between the two sites. This may be due to local atmospheric conditions at WOO which suppressed the nucleation, or it may be the result of two individual nucleation events that occurred at QUT and ROC simultaneously. Further analysis was required in order to explain this phenomenon, including data for gaseous pollutants, meteorological conditions, $\mathrm{PM}_{2.5}$ and $\mathrm{PM}_{10}$ which will be discussed in following section.

\subsubsection{Comparison of the two case studies}

The back-trajectories for the 17 July 2009 and 9 September 2009 events were calculated for the first two hours of the 

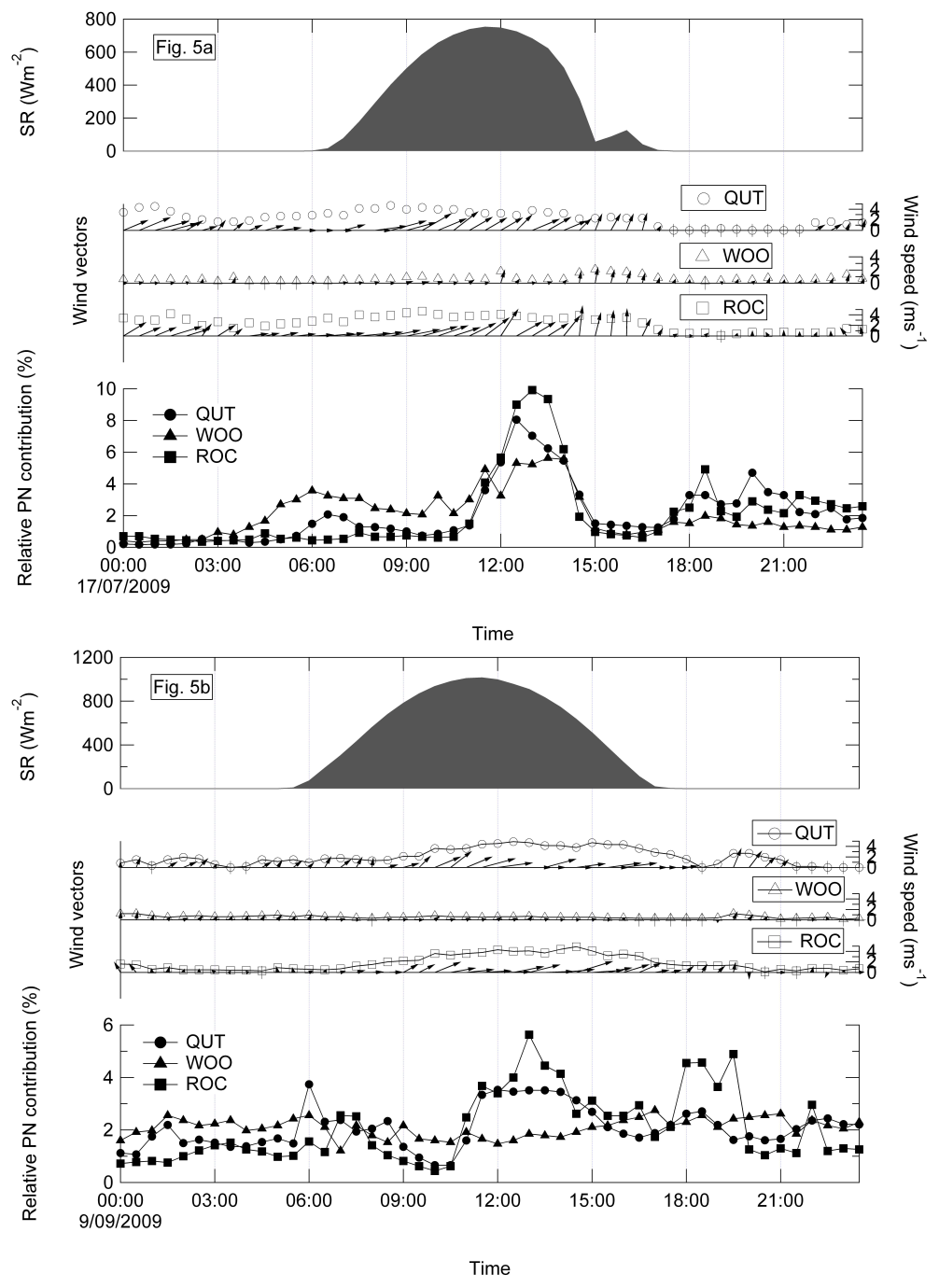

Fig. 5. Time series plot of parameters measured on (a) 17 July 2009 and (b) 9 September 2009. From bottom to top: (i) relative PNC measured at QUT, WOO and ROC; (ii) wind vectors for QUT, WOO and ROC; and (iii) solar radiation (SR) at ROC.

nucleation events (see Fig. 6a-b). The results suggest that the air masses at each site originated from the same region on both occasions, which means that the absence of a nucleation event at WOO on 9 September 2009 is likely to be the result of other variable factors such as local emission sources and/or meteorological conditions.

In order to further investigate the similarities and differences between these two cases, average $\mathrm{PNC}$ and $\mathrm{PM}_{10}$, as well as gaseous pollutants such as $\mathrm{CO}$ and $\mathrm{NO}_{\mathrm{x}}$, and meteorological conditions including temperature, relative humidity and wind speed, were compared for WOO and ROC (see Table 3). Overall, no significant differences in temperature or relative humidity were observed, although a relatively lower wind speed was observed at WOO $\left(\sim 1 \mathrm{~ms}^{-1}\right)$ compared to that of ROC $\left(\sim 3-4 \mathrm{~ms}^{-1}\right)$ during both events. The temperature differences during those events at WOO and ROC were small, implying that the impacts of height of mixing layer on both locations were similar. This observation (with high $r^{2}$ (QUT-ROC) and relatively low $r^{2}$ (QUT-WOO), $r^{2}$ (WOOROC)) was also found on 30 May, 8 June, 8 August and 16 October 2009. For gaseous pollutants, the mixing ratios for $\mathrm{NO}_{\mathrm{x}}$ at WOO and ROC remained the same for both events, while a relatively higher mixing ratio of $0.29 \mathrm{ppm}$ for $\mathrm{CO}$ was observed at WOO on 9 September 2009, compared to $0.19 \mathrm{ppm}$ on 17 July 2009 . A relatively higher $\mathrm{CO} / \mathrm{NO}_{\mathrm{x}}$ ratio of $\sim 5.8$ was also observed at WOO on 9 September 2009 compared to $\sim 3.8$ on 17 July 2009 .

In terms of particle mass, the $\mathrm{PM}_{10}$ at $\mathrm{WOO}$ was $13.6 \mathrm{mg} \mathrm{cm}^{-3}$ on 17 July 2009 , compared to $17.8 \mathrm{mg} \mathrm{cm}^{-3}$ on 9 September 2009 (an increase of $30.9 \%$ ). On the other hand the $\mathrm{PM}_{10}$ at ROC was $7.0 \mathrm{mg} \mathrm{cm}^{-3}$ on 17 July 2009 , compared to $6.8 \mathrm{mg} \mathrm{cm}^{-3}$ on 9 September 2009 (an decrease of $2.9 \%$ ). A higher number of pre-existing particles in the atmosphere can act a strong sink for condensation nuclei, 
Table 2. The $r^{2}$ values for PNC at QUT, WOO and ROC during nucleation growth events ( $r^{2}$ values $>0.4$ are bolded). Nucleation events were classified into Class Ia/b where the particle growth rate can be determined and Class II where the banana shape still observable, but the data fluctuates to such an extent that formation rate calculation is impractical. More detailed explanation of class type can be found in Cheung et al. (2011).

\begin{tabular}{|c|c|c|c|c|}
\hline Event types & Date & $\begin{array}{r}r^{2} \\
\text { (QUT-ROC) }\end{array}$ & $\begin{array}{r}r^{2} \\
\text { (QUT-WOO) }\end{array}$ & $\begin{array}{r}r^{2} \\
(\mathrm{WOO}-\mathrm{ROC})\end{array}$ \\
\hline \multirow{4}{*}{ Class Ia } & 15 Feb 2009 & 0.42 & & \\
\hline & 16 Feb 2009 & 0.11 & & \\
\hline & 28 Apr 2009 & 0.52 & & \\
\hline & 29 Apr 2009 & 0.17 & & \\
\hline \multirow{13}{*}{ Class Ib } & 30 Mar 2009 & 0.00 & & \\
\hline & 17 May 2009 & 0.74 & & \\
\hline & 6 Jun 2009 & 0.02 & 0.42 & 0.10 \\
\hline & 18 Jul 2009 & 0.10 & 0.58 & 0.03 \\
\hline & 28 Jul 2009 & 0.19 & 0.23 & 0.01 \\
\hline & 1 Aug 2009 & 0.00 & 0.46 & 0.01 \\
\hline & 2 Aug 2009 & 0.13 & 0.02 & 0.16 \\
\hline & 8 Aug 2009 & 0.53 & 0.25 & 0.09 \\
\hline & 9 Aug 2009 & 0.39 & 0.11 & 0.15 \\
\hline & 18 Aug 2009 & 0.82 & 0.66 & 0.41 \\
\hline & 9 Sep 2009 & 0.79 & 0.00 & 0.01 \\
\hline & 8 Oct 2009 & 0.16 & 0.33 & 0.59 \\
\hline & 21 Oct 2009 & 0.08 & 0.12 & 0.68 \\
\hline \multirow{20}{*}{ Class II } & 9 Feb 2009 & 0.09 & & \\
\hline & 26 Feb 2009 & 0.00 & & \\
\hline & 27 Feb 2009 & 0.19 & & \\
\hline & 28 Feb 2009 & 0.00 & & \\
\hline & 15 Mar 2009 & 0.64 & & \\
\hline & 16 Mar 2009 & 0.25 & & \\
\hline & 17 Mar 2009 & 0.54 & & \\
\hline & 22 Mar 2009 & 0.26 & & \\
\hline & 5 Apr 2009 & 0.00 & & \\
\hline & 12 May 2009 & 0.25 & & \\
\hline & 21 May 2009 & 0.04 & 0.01 & 0.38 \\
\hline & 30 May 2009 & 0.71 & 0.02 & 0.04 \\
\hline & 8 Jun 2009 & 0.53 & 0.08 & 0.05 \\
\hline & 17 Jul 2009 & 0.95 & 0.71 & 0.75 \\
\hline & 15 Aug 2009 & 0.28 & 0.77 & 0.20 \\
\hline & 10 Sep 2009 & 0.65 & 0.56 & 0.45 \\
\hline & 14 Sep 2009 & 0.16 & 0.17 & 0.20 \\
\hline & 16 Oct 2009 & 0.46 & 0.05 & 0.10 \\
\hline & 24 Oct 2009 & 0.15 & 0.51 & 0.67 \\
\hline & 3 Dec 2009 & 0.05 & 0.02 & 0.21 \\
\hline
\end{tabular}

Table 3a. Average values of measured parameters of WOO and ROC from 08:00-16:00 on 17 Jul 2009. A standard deviation showed in bracket.

\begin{tabular}{rrrrrrrr}
\hline & $\mathrm{PN}\left(10^{3} \mathrm{~cm}^{-3}\right)$ & $\mathrm{PM}_{10}\left(\mu \mathrm{g} \mathrm{m}^{-3}\right)$ & $\mathrm{CO}(\mathrm{ppm})$ & $\mathrm{NO}_{\mathrm{x}}(\mathrm{ppm})$ & $\mathrm{Temp}\left({ }^{\circ} \mathrm{C}\right)$ & $\mathrm{RH}(\%)$ & Wind Speed $\left(\mathrm{ms}^{-1}\right)$ \\
\hline WOO & $8.3(3.9)$ & $13.6(3.5)$ & $0.19(0.15)$ & $0.05(0.02)$ & $17.7(1.8)$ & $47.8(5.8)$ & $1.0(0.5)$ \\
\hline ROC & $3.0(3.2)$ & $7.0(0.9)$ & $\mathrm{n} / \mathrm{a}$ & $0.00(0.00)$ & $15.6(2.8)$ & $48.6(10.1)$ & $3.8(0.4)$
\end{tabular}


Table 3b. Average values of measured parameters of WOO and ROC from 08:00-16:00 on 9 Sep 2009. A standard deviation showed in bracket.

\begin{tabular}{rrrrrrrr}
\hline & $\mathrm{PN}\left(10^{3} \mathrm{~cm}^{-3}\right)$ & $\mathrm{PM}_{10}\left(\mu \mathrm{g} \mathrm{m}^{-3}\right)$ & $\mathrm{CO}(\mathrm{ppm})$ & $\mathrm{NO}_{\mathrm{x}}(\mathrm{ppm})$ & $\mathrm{Temp}\left({ }^{\circ} \mathrm{C}\right)$ & $\mathrm{RH}(\%)$ & Wind Speed $\left(\mathrm{ms}^{-1}\right)$ \\
\hline WOO & $5.6(0.7)$ & $17.8(7.2)$ & $0.29(0.36)$ & $0.05(0.02)$ & $24.0(1.5)$ & $33.0(6.8)$ & $0.5(0.1)$ \\
\hline ROC & $2.6(1.6)$ & $6.8(3.3)$ & $\mathrm{n} / \mathrm{a}$ & $0.00(0.00)$ & $22.5(2.1)$ & $32.3(9.9)$ & $3.4(1.0)$ \\
\hline
\end{tabular}
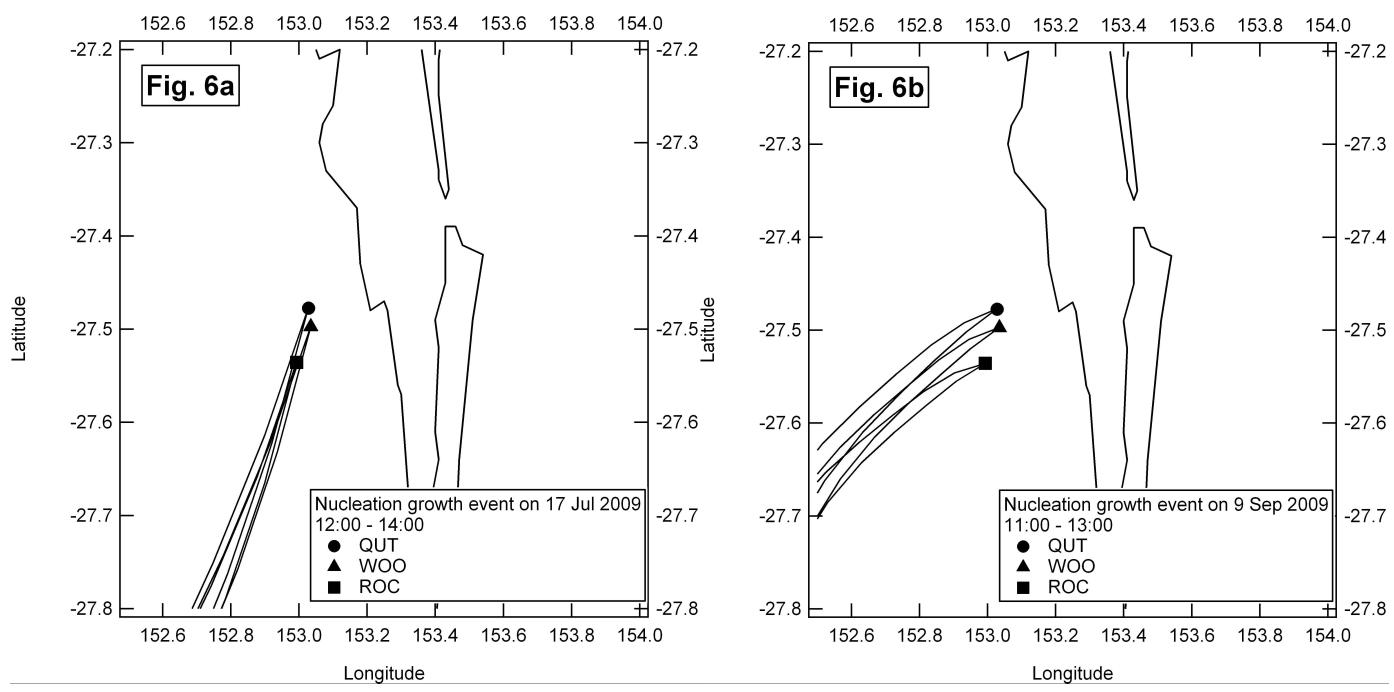

Fig. 6. Back-trajectories for the first two hours of each event: (a) 17 Jul 2009 and (b) 9 Sep 2009.

therefore suppressing new particle formation (Kerminen et al., 2001). In our previous study (Jayaratne et al, 2011), it has been shown that an increase of $\mathrm{PM}_{10}$ concentration in the environment leads to a sharp decrease in the number of ultrafine particles. Therefore, the relatively higher particle mass concentration of WOO on 9 September 2009, which is indicative of more pre-existing particles. This explains the suppression of the nucleation process at WOO on this day. Beside the influence of condensation sink on the suppression of nucleation, the coagulation scavenging may be another factor which removed the freshly formed particles in this case.

\subsection{Influence of upwind pollution on the particle numberconcentration in the downwind area}

In addition to the influence of regional pollution on PNC at each site, upwind pollution from a NE direction was also found to affect PNC. In order to characterise the influence of nucleation burst events on air quality downwind from larger pollution sources, we analysed the data from Cheung et al. (2011), based on 22 nucleation burst events that occurred at QUT during 2009, all of which were associated with NE winds that originated from the same direction as the Brisbane Airport, Oil Refinery and Port of Brisbane. Table 4 shows the Pearson's coefficient for PNC at QUT and ROC during the nucleation burst events. Since it takes about $30 \mathrm{~min}$ for air masses to move from QUT to ROC (assuming an average wind speed of $\sim 5 \mathrm{~ms}^{-1}$ during the event period), the $r^{2}$ values were also calculated based on data from $30 \mathrm{~min}$ later at ROC (e.g. 12:30 data from QUT was compared with 13:00 data for ROC).

From this table it can be seen that variations in PNC at QUT and ROC were correlated during most of the nucleation burst events. The "time shifted" $r^{2}$ values were higher than the original values in 11 out of the 22 cases (only the cases with shifted $r^{2} \geq 0.4$ were counted), indicating that the variation in PNC in the downwind area was associated with the air masses from the NE. In order to investigate this phenomenon further, we constructed a time series plot of the PNC and wind vectors at QUT and ROC for 25 October 2009 (see Fig. 7). On this day, the original $r^{2}$ calculated was 0.33 , and the "time shifted" $r^{2}$ was significantly improved to 0.82 . It can be seen that the highest PNC levels ( $12 \%$ contribution to total $\mathrm{PN}, \sim 80 \times 10^{3} \mathrm{~cm}^{-3}$ ) were associated with a pollution plume that blew in from the NE, which reached the CBD at around 11:00 a.m. As indicated by a particle burst observed at ROC around 12:00, this plume reached ROC around 30$60 \mathrm{~min}$ later. The $r^{2}$ value of 0.82 indicates that the increase in PNC at QUT and ROC were similar and back-trajectories calculated for QUT and ROC during the burst event confirmed that the air masses originated from same region (see Fig. 8). 


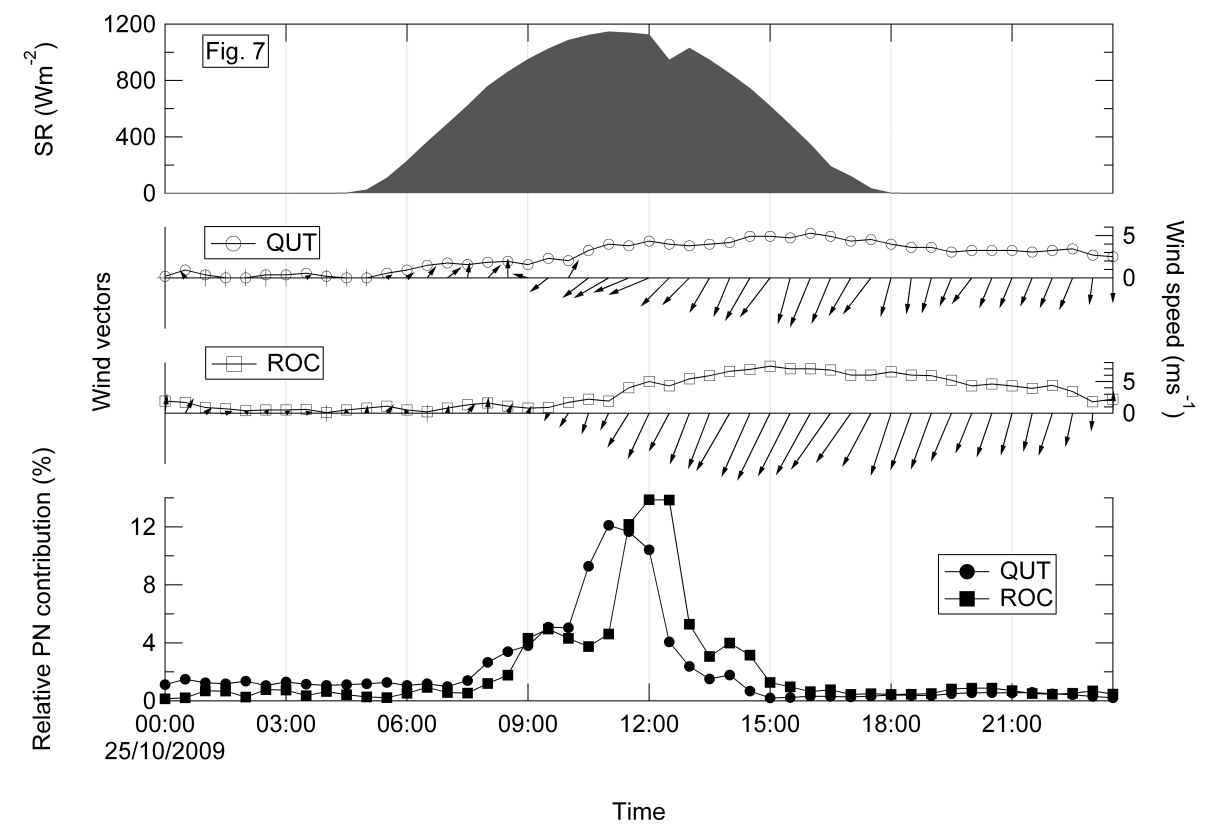

Fig. 7. Time series plot of parameters measured on 25 Oct 2009. From bottom to top: (i) number concentration of nucleation and Aitken modes particles; (ii) relative particle number concentration measured at QUT and ROC; (iii) wind vectors at QUT and ROC; and (iv) solar radiation (SR) at Rocklea.

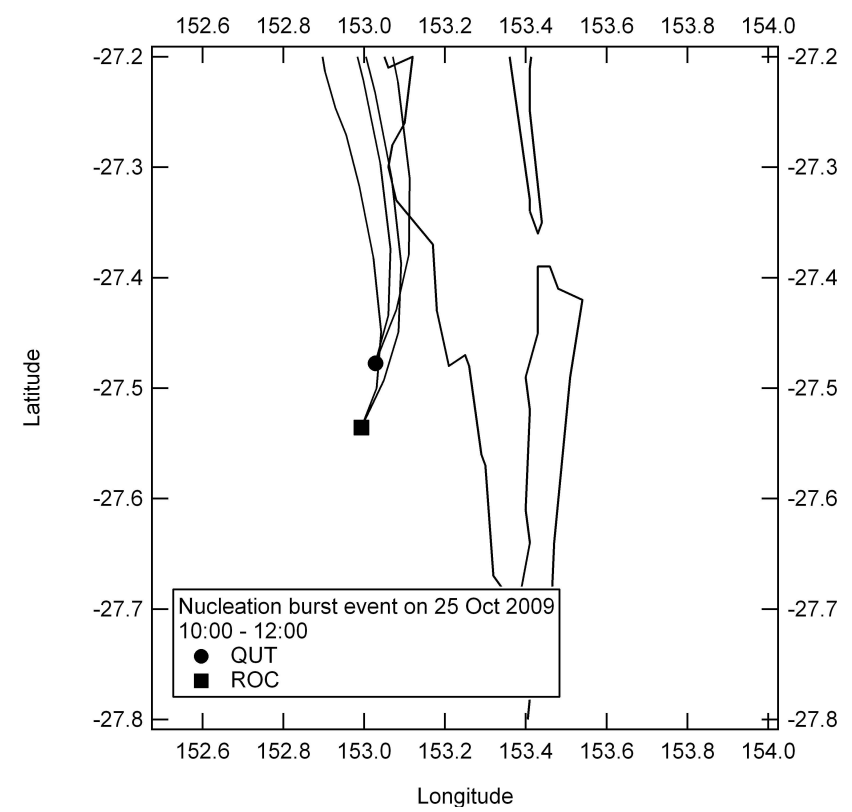

Fig. 8. Back-trajectories calculated for the burst events on 25 Oct 2009.

To further evaluate the impact of the nucleation burst events on the PNC in the semi-urban area of ROC, we determined the enrichment factor of PNC by calculating the ratio of maximum to minimum PNC during the period 08:0016:00. On 25 Oct 2009, PNC increased to about 11.6 times higher than the minimum PNC, which indicates that the ur- ban/industrial pollution plume had a significant effect on PNC in the semi-urban area. The enrichment factor for other nucleation burst event days are listed in Table S1, in the Supplement. The average enrichment factor for PNC at ROC as a result of upwind urban pollution during the nucleation burst events was 15.4 .

\section{Conclusions}

PNC variation was investigated in urban, roadside and semiurban areas of Brisbane during 2009. Overall, significant diurnal variation was observed at QUT and WOO during weekdays, and PNC peaks were observed at all three sites around noon, which corresponded with the highest solar radiation levels and suggested that the PNC was associated with new particle formation by photochemical reactions. Wind rose plots of PNC showed that highly polluted air plumes blew in from a NE direction, which is consistent with the direction of major urban and industrial areas, and although PNC did not show a significant correlation between the three sites, concentrations were found to be closely correlated during nucleation growth events. In addition, PNC at the semi-urban site of ROC was significantly influenced by the upwind urban pollution coming from the NE, with an average enrichment factor of 10.8. This study provides an insight into the influence of regional nucleation events on PNC in the Brisbane region and is the first study to quantify the effect of urban pollution on semi-urban PNC. The findings of this study 
Table 4. The $r^{2}$ values for PNC at QUT and ROC during nucleation burst events. Only data observed between 08:00-16:00 has been used (shifted $r^{2}$ values larger than original $r^{2}$, and the values $\geq 0.4$ are bolded).

\begin{tabular}{lrr}
\hline Date & $r^{2}$ & $\begin{array}{r}r^{2}(\text { ROC data } \\
\text { shifted } 30 \text { min })\end{array}$ \\
\hline 8 Feb 2009 & 0.88 & 0.94 \\
24 Feb 2009 & 0.04 & 0.02 \\
15 Mar 2009 & $\mathbf{0 . 6 4}$ & $\mathbf{0 . 8 2}$ \\
14 Apr 2009 & $\mathbf{0 . 5 2}$ & $\mathbf{0 . 8 7}$ \\
3 Sep 2009 & $\mathbf{0 . 7 5}$ & $\mathbf{0 . 8 7}$ \\
16 Sep 2009 & $\mathbf{0 . 7 9}$ & $\mathbf{0 . 9 3}$ \\
17 Sep 2009 & $\mathbf{0 . 4 0}$ & $\mathbf{0 . 6 4}$ \\
20 Oct 2009 & 0.56 & 0.40 \\
22 Oct 2009 & 0.66 & 0.65 \\
25 Oct 2009 & $\mathbf{0 . 3 3}$ & $\mathbf{0 . 8 2}$ \\
28 Oct 2009 & $\mathbf{0 . 3 3}$ & $\mathbf{0 . 7 3}$ \\
29 Oct 2009 & $\mathbf{0 . 2 1}$ & $\mathbf{0 . 6 6}$ \\
31 Oct 2009 & 0.30 & 0.09 \\
2 Nov 2009 & $\mathbf{0 . 5 1}$ & $\mathbf{0 . 8 1}$ \\
5 Nov 2009 & 0.56 & 0.28 \\
7 Nov 2009 & 0.31 & 0.00 \\
11 Nov 2009 & 0.58 & 0.54 \\
12 Nov 2009 & 0.90 & 0.81 \\
14 Nov 2009 & 0.00 & 0.02 \\
24 Nov 2009 & 0.37 & 0.23 \\
26 Nov 2009 & $\mathbf{0 . 8 2}$ & $\mathbf{0 . 9 8}$ \\
24 Dec 2009 & 0.00 & 0.08 \\
\hline Average & 0.48 & 0.55 \\
\hline
\end{tabular}

are useful for environmental management and assessment in regard to $\mathrm{PNC}$.

\section{Supplementary material related to this article is available online at: http://www.atmos-chem-phys.net/12/4951/2012/ acp-12-4951-2012-supplement.pdf.}

Acknowledgements. This project was supported by the Australian Research Council and Queensland Transport through Linkage Grant LP0882544. We would also like to thank the Department of Environmental Resource and Management, Queensland for providing the air monitoring data; and the Queensland Bureau of Meteorology for providing the meteorological data.

Edited by: C. K. Chan

\section{References}

Charlson, R. J., Schwartz, S. E., Hales, J. M., Cess, R. D., Coaklev Jr., J. A., Hansen, J. E., and Hofmann, D. J.: Climate forcing by anthropogenic aerosols, Science, 255, 423-430, 1992.
Cheung, H. C., Morawska, L., and Ristovski, Z. D.: Observation of new particle formation in subtropical urban environment, Atmos. Chem. Phys., 11, 3823-3833, doi:10.5194/acp-11-38232011, 2011.

Donaldson, K., Li, X. Y., and MacNee, W.: Ultrafine (nanometre) particle mediated lung injury, J. Aerosol. Sci., 29, 553-560, 1998.

Draxler, R. R.: HYSPLIT4 user's guide, NOAA Tech. Memo. ERLARL-230, NOAA Air Resources Laboratory, Silver Spring, MD, 1999.

Draxler, R. R. and Hess, G. D.: Description of the HYSPLIT_4 modeling system. NOAA Tech. Memo. ERLARL-224, NOAA Air Resources Laboratory, Silver Spring, MD, 1997.

Draxler, R. R. and Hess, G. D.: An overview of the HYSPLIT_4 modeling system of trajectories, dispersion, and deposition, Aust. Meteorol. Mag., 47, 295-308, 1998.

Holmén, B. A. and Niemeier, D. A.: Characterizing the effects of driver variability on real-world vehicle emissions, Transport Res. D-Tr. E., 3, 117-128, 1997.

Hudda, N., Cheung, K., Moore, K. F., and Sioutas, C.: Intercommunity variability in total particle number concentrations in the eastern Los Angeles air basin, Atmos. Chem. Phys., 10, 11385-11399, doi:10.5194/acp-10-11385-2010, 2010.

Hussein, T., Puustinen, A., Aalto, P. P., Mäkelä, J. M., Hämeri, K., and Kulmala, M.: Urban aerosol number size distributions, Atmos. Chem. Phys., 4, 391-411, doi:10.5194/acp-4-391-2004, 2004.

Hussein, T., Martikainen, J., Junninen, H., Sogacheva, L., Wagner, R., Dal Maso, M., Riipinen, I., Aalto, P. P., and Kulmala, M.: Observation of regional new particle formation in the urban atmosphere, Tellus, 60B, 509-521, 2008.

Jaffe, D., Mckendry, I., Anderson, T., and Price, H.: Six "new" episodes of trans-Pacific transport of air pollutants, Atmos. Environ., 37, 391-401, 2003.

Jayaratne, E. R., Johnson, G. R., McGarry, P., Cheung, H. C. and Morawska, L.: Characteristics of airborne ultrafine and coarse particles during the Australian dust storm of 23 September 2009, Atmos. Environ., 45, 3996-4001, 2011.

Kerminen, V.-M., Pirjola, L., and Kulmala, M.: How significantly does coagulational scavenging limit atmospheric particle production?, J. Geophys. Res., 106, 24119-24125, doi:10.1029/2001JD000322, 2001.

Mazaheri, M., Johnson, G. R., and Morawska, L.: Particle and Gaseous Emissions from Commercial Aircraft at Each Stage of the Landing and Takeoff Cycle, Environ. Sci. Technol., 43, 441446, 2009.

Mejía, J. F., Wraith, D., Mengersen, K., and Morawska, L.: Trends in size classified particle number concentration in subtropical Brisbane, Australia, based on a 5 year study, Atmos. Environ., 41, 1064-1079, 2007.

Mejía, J. F., Morawska, L., and Mengersen, K.: Spatial variation in particle number size distributions in a large metropolitan area, Atmos. Chem. Phys., 8, 1127-1138, doi:10.5194/acp-8-11272008, 2008.

Morawska, L., Thomas, S., Bofinger, N., Wainwright, D., and Neale, D.: Comprehensive characterization of aerosols in a subtropical urban atmosphere: Particle size distribution and correlation with gaseous pollutants, Atmos. Environ., 32, 2467-2478, 1998. 
Morawska, L., Ristovski, Z., Jayaratne, E. R., Keogh, D. U., and Ling, X.: Ambient nano and ultrafine particles from motor vehicle emissions: Characteristics, ambient processing and implications on human exposure, Atmos. Environ., 42, 8113-8138, 2008.

Pey, J., Querol, X., Alastuey, A., Rodàiguez, S., Putaud, J. P., and Van Dingenen, R.: Source apportionment of urban fine and ultrafine particle number concentration in a Western Mediterranean city, Atmos. Environ., 43, 4407-4415, 2009.

Qian, S., Sakurai, H., and McMurry, P. H.: Characteristics of regional nucleation events in urban East St. Louis, Atmos. Environ., 41, 4119-4127, 2007.
Sinha, P., Hobbs, P. V., Yokelson, R. J., Christian, T. J., Kirchstetter, T. W., and Bruintjes, R.: Emissions of trace gases and particles from two ships in the southern Atlantic Ocean, Atmos. Environ., 37, 2139-2149, 2003.

Stanier, C. O., Khlystov, A. Y., and Pandis, S. N.: Nucleation events during the Pittsburgh air quality study: description and relation to key meteorological, gas phase and aerosol parameters, Aerosol Sci. Tech., 38, 253-264, 2004.

Stolzenburg, M. R., McMurry, P. H., and Sakurai, H.: Growth rates of freshly nucleated atmospheric particles in Atlanta, J. Geophys. Res., 110, D22S05, doi:10.1029/2005JD05935, 2005.

Watson, J. G.: Visibility: Science and Regulation, J. Air Waste Manage., 52, 628-713, 2002. 